\title{
Control of Maglev Trains Moving on Bridges During Foundation Settlements
}

\author{
S.H. Ju \\ Department of Civil Engineering \\ National Cheng-Kung University \\ Tainan City, Taiwan, R.O.C \\ Y.S. Ho \\ Department of Civil Engineering \\ National Cheng-Kung University \\ Tainan City, Taiwan, R.O.C
}

\begin{abstract}
This paper investigates the control and safety of a series of maglev trains moving on multi-span simply supported bridges with the foundation settlements. To control the dynamic response of the maglev trains, a PI (proportional-integral) controller with constant tuning gains is applied. The finite element results indicate that the influences of the rail irregularities are obvious. However, the allowable vertical settlement and the Y-deflection of the bridge, which is caused by the $X$-rotation can be significantly improved when the lateral electromagnetic force is enlarged.
\end{abstract}

Keywords-Maglev train; PI control, Rail irregularity; Finite element method; Foundation settlement; Newmark method

\section{INTRODUCTION}

The maglev train is gradually playing an important role because of the advantages it brings to the society, such as lower power consumption, less noise and more safety. In the past few decades, many researchers make their efforts in this topic, such as Cai et al. in 1994 [1] studied the dynamic interactions between the vehicle and guideway of a high-speed maglev train with an emphasis on the effects of vehicle and guideway parameters. Yau in 2009 [2] developed a neuro-PI (proportional-integral) controller to control the dynamic response of the maglev vehicles. This study also demonstrated that a trained neuro-PI controller had the ability to control the acceleration amplitude for running maglev vehicles. Lee et al. in 2009 [3] found that the air gap of the vehicle was strongly affected by vehicle speed, tract roughness and especially the guideway deflection ratio. The span length and damping ratio of the guideway structure did not affect the air gap. Yim et al. in 2009 [4] predicted the curving performance with the greatest accuracy possible, in order to improve electromagnetic suspension. Yau in 2009 [5] indicated that the increase in levitation gap for a maglev vehicle might result in larger vehicle's response, but the response of the maglev vehicle with smaller air gap would be significantly amplified at higher speeds once ground settlement appears at the supports. Ren et al. in 2010 [6] showed that the vehicle model with 16 forces turned out to be the most appropriate simplification. Moreover, the influence of a vehicle/guideway interaction was considerable when the traveling velocity reached the certain

\author{
C.C. Leong \\ Department of Civil Engineering \\ National Cheng-Kung University \\ Tainan City, Taiwan, R.O.C
}

value. Song in 2008 [7] proposed a three-dimensional (3D) finite element analysis model of guideway structures considering ultra high-speed magnetic levitation train-bridge interaction. Yang and Yau in 2011 [8] presented an iterative interacting method for analyzing the dynamic response of a maglev train traveling on an elevated guideway. Ju. et. al in 2014 [9] investigated the safety of maglev trains moving on bridges using finite element analyses.

\section{CONTROL SYSTEM OF MAGLEV TRAINS}

The maglev system can be mainly separated into two parts according to the suspension modes: one is called the EMS (Electro Magnetic Suspension) system, which is developed by Germany, depends the attractive forces produced by electromagnets to levitate the vehicle; another is called the EDS (Electro Dynamic Suspension) system, which is constructed by Japan, uses the repulsive forces of superconducting materials to lift the vehicle up. Here, an EMS system maglev train is examined, and the levitation is provided by an electromagnet which is connected to the primary suspension. The current flowing through the circuit and the distance between the electromagnet and the guideway will be considered as the main variables to decide the electromagnetic force, as in several earlier studies [10,11,12], and thus:

$$
G_{i}^{t}\left(i_{i}^{t}, h_{i}^{t}\right)=K_{0}\left(\frac{i_{i}^{t}}{h_{i}^{t}}\right)^{2}=K_{0} \gamma_{i}^{t^{2}}
$$

where the superscript (t) indicates the current time and the suffix (i) indicates the ith magnetic wheel, $K_{0}$ is a coupling factor related to the cross-sectional area of the core, the number of turns of the windings and the permeability of free space. The variable $i_{i}^{t}$ indicates the control current flowing through the circuit, and $h_{i}^{t}$ indicates the height of the levitation gap as follows:

$$
h_{i}^{t}=h_{0}+y_{i}^{t}-u_{d}\left(x_{i}^{t}\right)+r_{v}\left(x_{i}^{t}\right)
$$


where $h_{0}$ is the desired height at the static equilibrium state, $y_{i}^{t}$ is the vertical displacement of the ith magnetic wheel, $x_{i}^{t}$ is the global X coordinate at the ith magnetic wheel, $u_{d}\left(x_{i}^{t}\right)$ is the deflection of the beam caused by the ith magnetic wheel, and $r_{v}\left(x_{i}^{t}\right)$ is the irregularity of the guideway. Besides, we define $\gamma_{i}^{t}=i_{i}^{t} / h_{i}^{t}$ in equation (1) for the simplicity. A sample function from Au et al. in 2002 [13] is used in this study.

$$
r_{v}\left(x_{i}^{t}\right)=\sum_{k=1}^{N} a_{k} \cos \left(\omega_{k} x_{i}^{t}+\phi_{k}\right)
$$

where $a_{k}$ is the amplitude, $\omega_{k}$ is a frequency $(\mathrm{rad} / \mathrm{s})$ within the upper and lower limits of the frequency [ $\omega_{l}, \omega_{u}$ ], $\phi_{k}$ is a random phase angle in the interval $[0,2 \pi]$, and $\mathrm{N}$ is the total number of terms. The parameters $a_{k}$ and $\omega_{k}$ are computed by:

$$
\begin{gathered}
a_{k}=2 \sqrt{G_{r r}\left(\omega_{k}\right) \Delta \omega}, \omega_{k}=\omega_{l}+(k-1 / 2) \Delta \omega, \alpha v \delta \\
\Delta \omega=\left(\omega_{u}-\omega_{l}\right) / N \\
G_{r r}(\omega)=\frac{A_{r} \omega_{2}^{2}\left(\omega^{2}+\omega_{1}^{2}\right)}{\omega^{4}\left(\omega^{2}+\omega_{2}^{2}\right)}, \alpha \nu \delta \kappa=1,2,, \mathrm{~N}
\end{gathered}
$$

where $G_{r r}(\omega)$ is a power spectral density function, Ar is the roughness coefficient, and $\omega_{1}$ and $\omega_{2}$ are frequencies that use to decide the shape of $G_{r r}(\omega)$. Rail irregularity parameters in

\begin{tabular}{|c|c|c|c|c|c|}
\hline$A_{r}\left(\mathrm{~m}^{2} \mathrm{rad} / \mathrm{m}\right)$ & $\omega_{1}(\mathrm{rad} / \mathrm{m})$ & $\omega_{2}(\mathrm{rad} / \mathrm{m})$ & $\begin{array}{l}\omega_{l}(\mathbf{r a d} / \mathrm{m} \\
\end{array}$ & $\begin{array}{l}\omega_{u}(\mathrm{rad} / \mathrm{m} \\
\end{array}$ & $N$ \\
\hline $2.75 \mathrm{E}-8$ & 0 & 0.8245 & 0.1 & 6.28 & $\begin{array}{l}200 \\
0 \\
\end{array}$ \\
\hline
\end{tabular}
this study are shown in Table 1.

TABLE I. THE Y-AND Z-DIRECTION RAIL IRREGULARITY PARAMETERS IN THIS STUDY.

In the static equilibrium state, the maglev train will be levitated by the electromagnetic force, implying equalization between the weight of the maglev train and the electromagnetic force,

$$
G_{i}\left(i_{0}, h_{0}\right)=K_{0}\left(\frac{i_{0}}{h_{0}}\right)^{2}=K_{0}\left(\gamma_{0}\right)^{2}=p_{0}
$$

where $i_{0}$ and $h_{0}$ are the desired values of the control current and the height of levitation gap, respectively. $p_{0}$ is the static load acting on the magnetic wheel due to the weight of the maglev train. Similarly, $\gamma_{0}$ is equal to $i_{0} / h_{0}$. For the feedback control of this maglev vehicle system, a controller, which is called PI (proportional integral) controller, is applied due to its simplicity. It can compute the "error" value which indicates the difference between the desired operating value and the current value, and minimize the error at the next computation step by tuning the input value of the controller. The control error can be written as:

$$
e_{i}^{t}=\gamma_{0}-\gamma_{i}^{t}
$$

Before using this controller, we should consider the relationship between the control current and the control voltage, since they are the essential values in the control of the maglev vehicle system. Their relation is given by $[5,12,14]$

$$
\Gamma_{0} \dot{\gamma}_{i}+R_{0} h_{i}(t) \gamma_{i}=V_{i}
$$

where $\Gamma_{0}=2 K_{0}$ is the initial inductance of the coil winding of the suspension magnet, $R_{0}$ is the coil resistance of the electronic circuit and $V_{i}$ is the control voltage of the maglev system. In fact, $V_{i}$ is also the output value of the PI controller, and has a significant role of the calculation of the corresponding control current. This control voltage will be compared with the reference value in order to form a new control error, and thus, a complete loop of the feedback control is achieved. The key equation of the controller is written as follows $[5,12,14]$ :

$$
V_{i}^{t+\Delta t}=K_{P} e_{i}^{t+\Delta t}+K_{I} \int_{0}^{t+\Delta t} e_{i}^{\tau} d \tau=K_{P} e_{i}^{t+\Delta t}+K_{I} \int_{0}^{t+\Delta t}\left(\gamma_{0}-\gamma_{i}^{\tau}\right) d \tau
$$
(9),

By using the trapezoidal rule in the integration of equation

$$
\begin{gathered}
V_{i}^{t+\Delta t}=K_{P} e_{i}^{t+\Delta t}+K_{I}\left[e_{a}+\left(\frac{e_{i}^{t}+e_{i}^{t+\Delta t}}{2}\right) \Delta t\right]_{\mathrm{O} \rho} \\
V_{i}^{t+\Delta}=K_{I}\left(e_{a}+\frac{\gamma_{0}-\gamma_{i}^{t}}{2} \Delta\right)+\left(K_{P}+\frac{K_{I}}{2} \Delta t\right)\left(\gamma_{0}-\gamma_{i}^{++\Delta}\right)
\end{gathered}
$$

Where

$$
e_{a}=\int_{0}^{t}\left(\gamma_{0}-\gamma_{i}^{\tau}\right) d \tau
$$

is the sum of the control error before time $\mathrm{t}$, in which this value is known at time $t+\Delta t, K_{P}$ and $K_{I}$ are the proportional gain and the integral gain as the tuning parameter, respectively, while $e_{i}^{t}$ and $e_{i}^{t+\Delta t}$ are the control error at time $t$ and $t+\Delta t$.

Applying the $\alpha$-method to equation (8) and combining with the equation (10),

$$
\Gamma_{0} \frac{\gamma_{i}^{t+\Delta t}-\gamma_{i}^{t}}{\Delta t}+A(1-\alpha) \gamma_{i}^{t}+A \alpha \gamma_{i}^{t+\Delta t}=B
$$

where $A=R_{0} h_{i}^{t+\Delta t}+K_{P}+\frac{K_{I}}{2} \Delta t$ and $B=K_{I} e_{a}+\frac{K_{I}\left(\gamma_{0}-\gamma_{i}^{t}\right)}{2} \Delta t+\left(K_{P}+\frac{K_{I}}{2} \Delta t\right) \gamma_{0}$.

Finally, one obtains: 


$$
\gamma_{i}^{i+\Delta t}=\left(\frac{\Gamma_{0}}{\Delta t}+A \alpha\right)^{-1}\left\{B+\left[\frac{\Gamma_{0}}{\Delta t}-(1-\alpha) A\right] \gamma_{i}^{t}\right\}
$$

All of the numerical procedures of the PI controller for the maglev train are involved in equation (13). Since there is only one unknown $h_{i}^{l+4}$ in the constant A at the right hand side of equation (13), we can compute the corresponding $\gamma_{i}^{++u}$ if the latest levitation height $h_{i}^{t+4 t}$ is known. The electromagnetic force $G_{i}$ at time $t+\Delta t$ can then be obtained from equation (1) by using $\gamma_{i}^{t+\Delta t}$.

\section{FinItE ELEMENT FORMULATION OF MAGLEV TRAINS}

Moving maglev trains are modeled as a combination of maglev wheel forces, spring-damper elements, lumped masses, and rigid links $[12,15]$. Using this finite element scheme, one can model complex vehicles, and obtain the following standard dynamic equation:

$$
[\mathrm{M}]\{\ddot{\mathrm{X}}\}+[\mathrm{C}]\{\dot{\mathrm{X}}\}+[\mathrm{K}]\{\mathrm{X}\}=\{\mathrm{F}\}
$$

where $[\mathrm{M}],[\mathrm{C}]$ and $[\mathrm{K}]$ are the mass, damping and stiffness matrices of the maglev trains and others, such as bridges and soil, which can be nonlinear, $\{\mathrm{F}\}$ is the force vector, and $\{\mathrm{X}\}$ is the displacement vector. The Newton-Raphson method can be used to solve this matrix equation.

\section{MAGLEV TRAIN-GUIDEWAY-BRIDGE INTERACTION ANALYSIS}

The maglev train has 12 carriages with the speed of $120 \mathrm{~m} / \mathrm{s}$ moving in the $\mathrm{X}$ direction, while the negative $\mathrm{Z}$ axis is the gravity direction. Each carriage contains four bogies, and each bogie contains four maglev wheels. Figure 1 shows the maglev train model, which contains spring-dampers, rigid bodies, and lumped masses. These components can be appropriately simulated using the wheels, lumped masses, and spring-damper elements mentioned in Section 3. The bridge is a 50-span simply supported bridge. The time step length is 0.0005 seconds. The settlement is applied at $600 \mathrm{~m}$ of the bridge origin. After generating the foundation settlements and rotations, the vertical and lateral deflection can be produced for the foundation and the bridges respectively, to analyze the safety of maglev trains during these situations. In this section, some cases will be taken into account to observe the performances of the vertical levitation gap and lateral guidance gap of the maglev trains.

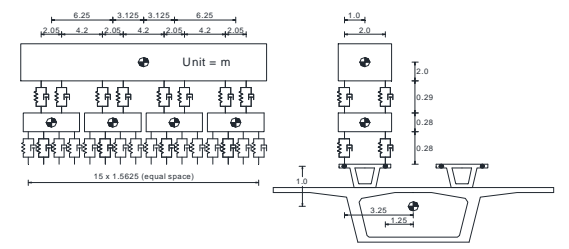

FIGURE I. MAGLEV TRAIN DIMENSIONS AND WITH FINITE ELEMENT MODEL.

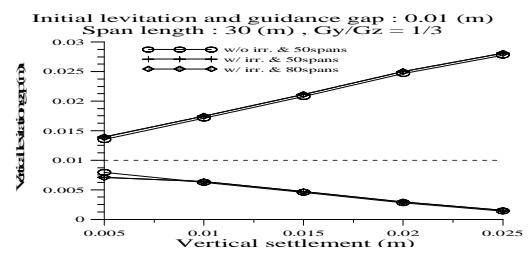

FIGURE II. VERTICAL LEVITATION GAP CHANGE OF SETTLEMENTS.

Figure 2 shows the influences of rail irregularities and the number of spans on the vertical levitation gap, in which the maximum vertical levitation gap among all the maglev wheels with $0.005 \mathrm{~m}, 0.01 \mathrm{~m}, 0.015 \mathrm{~m}, 0.02 \mathrm{~m}$ and $0.025 \mathrm{~m}$ vertical settlements are marked. The results show clearly that the performances with rail irregularities and 50 spans is almost the same as the one without rail irregularities, which implies that rail irregularities only influence slightly on the maximum vertical levitation gap. Then, the performances with 80 spans are the same as the one with 50 spans, mean that the results with 50 spans are accurate enough. Besides, no matter the rail irregularities or the span number is considered or not in $30 \mathrm{~m}$ span length, the allowable settlements should be within $0.025 \mathrm{~m}$.

Figures 3 and 4 show the maximum lateral guidance gaps and vertical levitation gaps among all the maglev wheels with related Y-deflections due to X-rotations. In Figure 3, it is obvious that the lateral guidance gaps can be enlarged efficiently with the increase of the lateral electromagnetic force Gy (since the vertical electromagnetic force $\mathrm{Gz}$ should be equal to the weight of the maglev train, it cannot be changed), i.e. the allowable Y-deflection can be increased from $0.013 \mathrm{~m}$ to 0.022 $\mathrm{m}$. In addition, the influence of rail irregularities is not apparent on this performance; however, when the Y-deflection due to Xrotation is smaller, the rail irregularities become more important to the lateral guidance gap. In Figure 4, the increase of lateral electromagnetic force Gy also has a significant effect on the vertical levitation gap. Since the $\mathrm{Z}$ deflection caused by the X-rotation is very small, the slopes of the results are also smaller than the one shown in Figure 3. Owing to this reason, the rail irregularities have the obvious influences on these results. It is more clearly on the maximum vertical levitation gaps because there is a constant difference exists between them, and this constant is the rail irregularity. For the minimum vertical levitation gaps, one can only see the effect of the Ydeflection due to X-rotation after $0.01 \mathrm{~m}$ since the Z-deflection is very small.

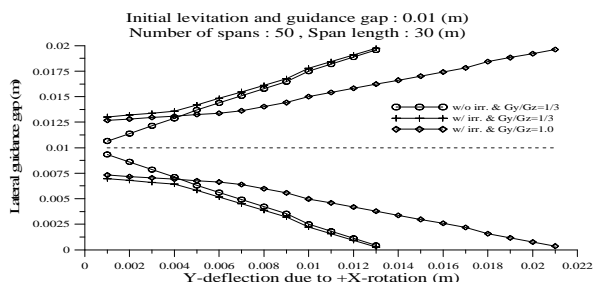

FIGURE III. THE INFLUENCES OF GY/GZ AND RAIL IRREGULARITIES ON LATERAL GUIDANCE GAP WITH THE CHANGE OF Y-DEFLECTION DUE TO +XROTATION. 


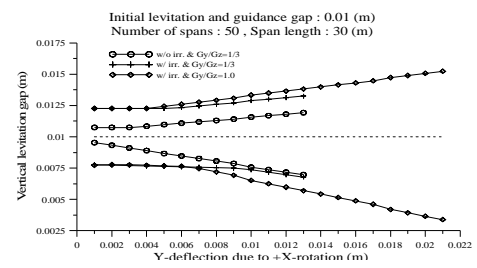

FIGURE IV. THE INFLUENCES OF GY/GZ AND RAIL IRREGULARITIES ON VERTICAL LEVITATION GAP WITH THE CHANGE OF Y-DEFLECTION DUE TO + X-ROTATION.

With the consideration of the settlement, the influence of the span length on vertical levitation gap and lateral guidance gap is shown in Figure 5, where $0.025 \mathrm{~m}$ settlements are applied. Notice that this allowable settlement is obtained when the span length is $30 \mathrm{~m}$, so the values of the vertical levitation gap and lateral guidance gap are used as the reference points. One can observe that the maximum vertical levitation gaps become larger with the decrease of the span length. It is because the settlement is generated by two adjacent girders, if the span becomes shorter, the angle of this settlement will become sharper, and furthermore the length of one carriage is $25 \mathrm{~m}$. Therefore, when the span length is shorter, the vertical levitation gap will be larger. Also, because of this reason, the same performance can also be seen in the minimum vertical levitation gap. In addition, there is no influence on the lateral guidance gap due to the settlement.

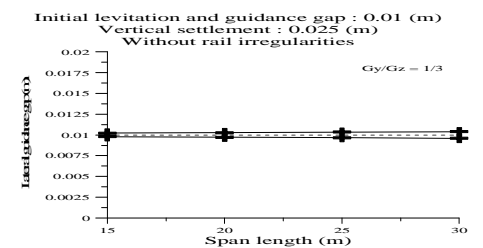

(a) Lateral levitation gap.

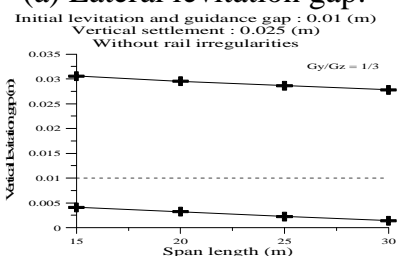

(b) Vertical guidance gap.

FIGURE V. THE LEVITATION AND GUIDANCE GAP WITH THE CHANGE OF SPAN LENGTH AND VERTICAL SETTLEMENTS (WITHOUT RAIL IRREGULARITIES,

$$
\mathrm{GY} / \mathrm{GZ}=1 / 3) \text {. }
$$

Figure 6 shows the relationship between the changes of the span length and the deflection of the girders. No matter how the span length changes, the influences of both the lateral guidance gap and vertical levitation gap due to the Y-deflections are very tiny, though there are still a little changes in the vertical levitation gap. For general, under the Y-deflection, the changes of span length do not produce a big effect on lateral guidance and vertical levitation gap.

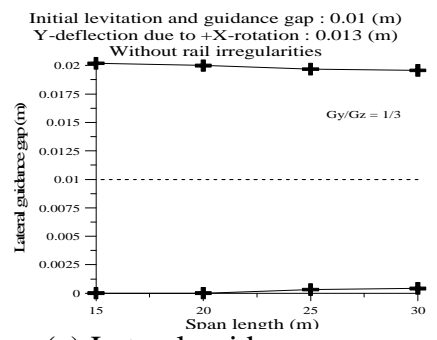

(a) Lateral guidance gap.

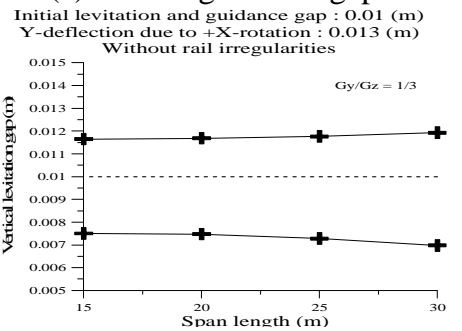

(b) Vertical levitation gap.

FIGURE VI. FIGURE 6: THE LEVITATION AND GUIDANCE GAP WITH THE CHANGE OF SPAN LENGTH AND Y-DEFLECTION DUE TO +X-ROTATION (WITHOUT RAIL IRREGULARITIES, GY/GZ=1/3).

\section{CONCLUSIONS}

In this study, to analyze the safety of the maglev trains moving on bridges with foundation settlements or rotations, a finite element method was developed to study this maglev train-guideway-bridge coupled system analysis. Combine the maglev wheel forces, spring-damper element, lumped mass element and the rigid links, a maglev train model is developed. The bridge model was also generated by using traditional finite elements. The PI controller is used for the control system of the maglev trains. Newmark method is then applied to solve the nonlinear dynamic equation. Finally, the analysis using the finite element method can begin.

The results of this study can be concluded as follows:

(1) For $30 \mathrm{~m}$ span length, the allowable vertical settlement for the vertical levitation gap is suggested to be $0.025 \mathrm{~m}$, and the Y-deflection caused by the X-rotation for lateral guidance gap is $0.013 \mathrm{~m}$.

(2) In the location with the vertical settlement or X-rotation, there is almost no influence of rail irregularities on the vertical levitation gap or lateral guidance gap if these two parameters are significantly enough. However, at other locations, the influences of rail irregularities become more obvious since the vertical settlement or X-rotation is not the main factor in these positions.

(3) The results show that 50 spans is accurate enough for the performances of vertical levitation gap and lateral guidance gap; the length of span also does not have great influences on the performances. However, the allowable vertical settlement and the Y-deflection caused by the X-rotation can be significantly improved when the lateral electromagnetic force is enlarged. 


\section{REFERENCES}

[1] Y. Cai, S.S. Chen, D.M. Rote, and H.T. Coffey. "Vehicle/guideway interaction for high speed vehicles on a flexible guideway," Journal of Sound and Vibration, Vol.175, 1994, pp.625-646.

[2] J.D. Yau. "Vibration control of maglev vehicles traveling over a flexible guideway," Journal of Sound and Vibration, Vol.321, 2009, pp. 184-200.

[3] J.S. Lee, S.D. Kwon, M.Y. Kim, and I.H. Yeo. "A parametric study on the dynamics of urban transit maglev vehicle running on flexible guideway bridges," Journal of Sound and Vibration, Vol.328, 2009, pp. 301-317.

[4] B.H. Yim, H.S. Han, J.K. Lee, and S.S. Kim. "Curving performance simulation of an EMS-type Maglev vehicle," Vehicle System Dynamics, Vol.47, 2009, pp.1287-1304.

[5] J.D. Yau. "Response of a maglev vehicle moving on a series of guideways with differential settlement," Journal of Sound and Vibration, Vol.324, 2009, pp.816-831.

[6] S. Ren, A. Romeijn, and K. Klap. "Dynamic simulation of the maglev vehicle/guideway system," Journal of Bridge Engineering, Vol.15, 2010, pp.269-278.

[7] M.K. Song. "Dynamic analysis of guideway structures by considering ultra high-speed Maglev train-guideway interaction," Structural Engineering and Mechanics,Vol.29, 2008, pp.355-380.

[8] Y.B. Yang, and J.D. Yau. "An iterative interacting method for dynamic analysis of the maglev train-guideway/foundation-soil system," Engineering Structures, Vol.33, 2011, pp.1013-1024.

[9] S.H. Ju, C.C. Leong, and Y.S. Ho. "Safety of maglev trains moving on bridges due to foundation settlements and earthquakes," Journal of Bridge Engineering ASCE, Vol.19, 2014, pp.91-100.

[10] J. Shi, Q.C. Wei, and Y. Zhao. "Analysis of dynamic response of the high-speed EMS maglev vehicle/guideway coupling system with random irregularity," Vehicle System Dynamics, Vol.45, 2007, pp.1077-1095.

[11] A. Bittar, and R.M. Sales. "H-2 and H-infinity Control for MagLev Vehicles," IEEE Control Systems, Vol.18, 1998, pp.18-25.

[12] S.H. Ju, Y.S. Ho, and C.C. Leong. "A finite element method for analysis of vibration induced by maglev trains," Journal of Sound and Vibration, Vol.331, 2012, pp.3751-3761.

[13] F.T.K. Au, J.J. Wang, and Y.K. Cheung. "Impact study of cable-stayed railway bridges with random rail irregularities, "Engineering Structures, Vol.24, 2002, pp.529-541.

[14] J.D. Yau. "Vibration control of maglev vehicles traveling over a flexible guideway, "Journal of Sound and Vibration, Vol.321, 2009, pp.184-200.

[15] S.H. Ju, H.D. Lin, C.C. Hsueh, and S.L. Wang. "A simple finite element model for vibration analyses induced by moving vehicles, "International Journal for Numerical Method in Engineering, Vol.68, 2006, pp.12321256 . 